\title{
Molecular Characterization of Staphylococcus warneri Catalase
}

\section{Fukuda, Daisuke}

Laboratory of Microbial Technology, Division of Microbial Science and Technology, Department of Bioscience and Biotechnology, Graduate School of Bioresource and Bioenvironmental Sciences, Kyushu University

\section{Mizuno, Kouhei}

Laboratory of Microbial Technology, Division of Microbial Science and Technology, Department of Bioscience and Biotechnology, Graduate School of Bioresource and Bioenvironmental Sciences, Kyushu University

Kohno, Mamiko

Laboratory of Microbial Technology, Division of Microbial Science and Technology, Department of Bioscience and Biotechnology, Graduate School of Bioresource and Bioenvironmental Sciences, Kyushu University

\section{Sonomoto, Kenji}

Laboratery of Microbial Technology, Division of Microbial Science and Technology, Department of Bioscience and Biotechnology, Faculty of Agriculture, Kyushu University

他

https://doi.org/10.5109/24372

出版情報: 九州大学大学院農学研究院紀要. 45 (1)，pp.213-223，2000-11. Kyushu University バージョン：

権利関係 : 
J. Fac. Agr., Kyushu Univ., 45 (1), 213-223 (2000)

\title{
Molecular Characterization of Staphylococcus warneri Catalase
}

\author{
Daisuke Fukuda*, Kouhei Mizuno*, Mamiko Kohno*, Kenji Sonomoto \\ and Ayaaki Ishizaki**
}

\begin{abstract}
Laboratory of Microbial Technology, Division of Microbial Science and Technology,
Department of Biosience and Biotechnology, Faculty of Agriculture, Kyushu University, Fukuoka 812-8581
\end{abstract}

(Received July 25, 2000 and accepted August 18, 2000)

\begin{abstract}
The catalase gene was cloned by screening a genomic DNA library of $S$. wameri ISK-1 strain with a strong catalase activity for complementation of the activity in catalase-deficient $E$. coli strain. Nucleotide sequence analysis of a $2.2-\mathrm{kb}$ DNA fragment revealed an open reading frame, called katA, encoding a peptide of 504 amino acids with a calculated molecular mass of $58 \mathrm{kDa}$. The predicted amino acid sequence showed high similarities with the monofunctional catalases. No similarities were found between katA product and catalase-peroxidase type enzymes. Electrophoretic mobility of $k a t A$ product was close to that of the previously purified ISK-1 catalase. Catalase activity was lost when the 135 amino acids were deleted from the C-terminal region.
\end{abstract}

\section{INTRODUCTION}

Reactive oxygen species (ROS) such as superoxide anion radical $\left(\mathrm{O}_{2}{ }^{-}\right)$and hydrogen peroxide $\left(\mathrm{H}_{2} \mathrm{O}_{2}\right)$ are produced as by-products of aerobic metabolism. The effects of ROS result in serious damages of various cellular components such as DNA, RNA, proteins and lipids (Imlay and Linn, 1988). Therefore, microorganism has evolved several enzymatic defense systems to eliminate the lethal effects of ROS (Storz et al., 1990). For example, superoxide anion radical is eliminated by dismutation to hydrogen peroxide by superoxide dismutase, and hydrogen peroxide is decomposed by catalase and peroxidase (Hassen and Fridovich, 1978). Catalase catalyzes the conversion of hydrogen peroxide to water and oxygen.

Escherichia coli is an only microorganism the catalase of which has been studied in depth (Triggs-Raine et al., 1988; von Ossowski et al., 1991). This organism is known to produce two species of hydroperoxidases (HPI and HPII) which are synthesized in quite different manners. HPI encoded by $k a t G$ exhibits a peroxidase activity in addition to the catalase activity which expresses in the exponential phase, and is governed by the global oxidative stress regulon OxyR (Loewen et al., 1983; Christman et al., 1989). HPII encoded by $k a t E$ possesses only catalase activity and is synthesized in the stationary growth phase. The expression of HPII requires a functional sigma factor RpoS (Loewen and Hengge-Aronis, 1994).

The genus Staphylococcus comprises a group of gram-positive and catalase-positive

\footnotetext{
* Laboratory of Microbial Technology, Division of Microbial Science and Technology, Department of Bioscience and Biotechnology, Graduate School of Bioresource and Bioenvironmental Sciences, Kyushu University

** Corresponding author (E-mail: ishizaki@agr.kyushu-u.ac.jp)
} 
facultative anaerobe. Mandell (1975) has described that the staphylococcal catalase acts as important role to tolerate against the lethal concentration of environmental hydrogen peroxide. Catalase has been used as a biochemical tool for differential identification of staphylococcal species (Raymond, 1976). But little is known about the character and structure of staphylococcal catalase, although some reports were focused on the physiological importance of this enzyme (Flowers et al., 1977). Moreover, staphylococcal catalase also plays an important role in food fermentations in which hydrogen peroxide accumulated causes color defects in food and kills available bacteria. For example, $S$. camosus catalase decomposes hydrogen peroxide formed as a metabolite by lactic acid bacteria (LAB) and may be important to reduce adverse effects on color, aroma and shelf-life of the fermented sausages (Hammes and Knauf, 1994). For these reasons, much attention is being denoted to the characteristic and structural properties of staphylococcal catalase.

S. warneri ISK-1 was isolated from well-aged Nukadoko, the rice bran packed fermentation bed for Japanese traditional pickled vegetables (Kimura et al., 1997). This strain possesses a strong catalase activity compared to other aerobic or anaerobic eubacteria (Mizuno et al., 2000). In Nukadoko, there exists many LAB, including bacteriocin-producing strains of Lactococcus lactis isolated from different well-aged Nukadoko (Ennahar et al., 1999). It is also assumed that $S$. wameri ISK-1 catalase contributes to survival of $\mathrm{LAB}$ against the environmental hydrogen peroxide and maintains the stable quality and microflora in Nukadoko for a long period. In this paper, we described about the cloning and characterization of the gene encoding the catalase of ISK-1 strain. Structural properties and phylogenetic relationships of this enzyme were also discussed. In our knowledge, this is the first investigation about the genetic characterization of staphylococcal catalase.

\section{MATERIALS AND METHODS}

\section{Bacterial strains, plasmid, and culture conditions}

Staphylococcus warneri ISK-1 was isolated in our laboratory (Kimura et al., 1997), and was grown at $37^{\circ} \mathrm{C}$ in MRS medium (Oxoid, Hampshire, England) Escherichia coli

Table 1. Bacterial strains used in this study

\begin{tabular}{clc}
\hline Strain & \multicolumn{1}{c}{ Descriptions } & References \\
\hline $\begin{array}{c}\text { Staphylococcus wameri } \\
\text { ISK-1 }\end{array}$ & Isolated in our laboratory from Nukadoko & Kimura et al., 1997 \\
$\begin{array}{c}\text { Escherichia coli } \\
\text { JM109 }\end{array}$ & $\begin{array}{l}\text { recA1 supE44 endA1 hsdR17 gyrA96 relAl } \\
\text { thi } \Delta(\text { lac-proAB })\end{array}$ & Yanisch-Perron et al., 1985 \\
MC1000 & $\begin{array}{l}\text { araD139 } \Delta(\text { ara-leu }) 7696 \text { galU galK } \Delta(174) \\
\text { rpsL thi }\end{array}$ & Nakagawa et al., 1996 \\
SN0029 & MC1000 katG: Cm katE::Km & Nakagawa et al., 1996 \\
\hline
\end{tabular}


JM109 (Toyobo, Osaka) and catalase-defective mutant E. coli SN0029 (katG::Cm, $k a t E:: \mathrm{Km}$ ) (Nakagawa et al., 1996) were grown at $37^{\circ} \mathrm{C}$ with shaking in Luria-Bertani (LB) medium or on LB $1.5 \%$ agar medium containing $40 \mu \mathrm{g} / \mathrm{ml}$ ampicillin. When the growing was appropriate for clonal selection, X-gal (5-bromo-4-isopropyl- $\beta$ -D-4-chloro-3-indol- $\beta$-D-galactopyranoside), IPTG (isopropylthio- $\beta$-D-galactosidase) and ampicillin were added at concentrations of $50,40,20 \mu \mathrm{g} / \mathrm{ml}$, respectively. Genotypic properties of these strains are indicated in Table 1. Cloning vector pUC18 (Toyobo) was used for cloning of $S$. warneri ISK-1 catalase gene.

\section{DNA preparation and manipulation}

Total chromosomal DNA from $S$. warmeri ISK-1 strain was isolated by applying a combination of the two methods (Marmur, 1961; Berns and Thomas, 1965). Plasmid DNA was purified from E. coli with Mag extractor plasmid extraction kit (Toyobo). Restriction endonuclease digestions, analyses and ligations were performed according to the methods of Sambrook et al. (1989). E. coli cells for electroporation were prepared according to the protocol recommended for the Gene Pulser apparatus (Bio-Rad, Hercules, CA, USA). Southern hybridization with nucleotide probes was performed by using the AlkPhos labeling system (Amersham Pharmacia Biotech, Uppsala, Sweden) according to the manufacture's protocol.

\section{Cloning of catalase gene}

The chromosomal DNA from ISK-1 strain was partially digested with restriction enzyme Sau3AI. A genomic library was constructed by ligating the Sau3AI fragments into the BamHI site of pUC18 vector and transformed into $E$. coli SN0029 by electroporation. The transformants were selected on LB agar containing $40 \mu \mathrm{g} / \mathrm{ml}$ ampicillin. The positive clone was screened for competence of catalase activity by applying a $3 \%$ hydrogen peroxide to agar plate and looking for the generation of oxygen bubbles.

\section{Nested deletion and DNA sequencing}

A catalase clone of 2.2-kb Sau3AI fragment in both orientations was digested with SmaI and SalI. Then nested deletion was performed with double-stranded Nested Deletion Kit outlined by the manufacture (Amesham Pharmacia Biotech). The transformants containing suitable size deletions were identified and sequenced. Sequencing reaction based on the method of Sanger et al. (1977) was performed with Auto Sequencer Core Kit (Toyobo) according to the instructions of the manufacture and using Cy-5 labeled M13 Universal and Reversal primers (Amersham Pharmacia Biotech). DNA sequence analyses were performed with ALF express (Amersham Pharmacia Biotech).

\section{Catalase activity staining}

Native PAGE was performed with $7-20 \%$ gradient polyacrylamide gels (Atto Co., Tokyo). The following staining for catalase activity was done as reported previously (Clare et al., 1984): the resulting native PAGE gel was soaked for $45 \mathrm{~min}$ in $50 \mathrm{mM}$ potassium-phosphate buffer ( $\mathrm{pH} \mathrm{7.0)}$ containing $50 \mu \mathrm{g} / \mathrm{ml}$ horseradish peroxidase (Wako Pure 
Chemical Industries, Osaka), followed by addition of $5 \mathrm{mM} \mathrm{H}_{2} \mathrm{O}_{2}$ and the incubation at $25^{\circ} \mathrm{C}$ for $10 \mathrm{~min}$. The gel was washed twice with distilled water and then soaked in the buffer containing $0.5 \mathrm{mg} / \mathrm{ml}$ diaminobenzidine (Nacalai Tesque) to develop the background brown color. No color would appeared in the area catalase depleted $\mathrm{H}_{2} \mathrm{O}_{2}$.

\section{Phylogenetic analyses}

S. wameri ISK-1 KatA and represetative 13 bacterial monofunctional catalases were used in this analysis. The Clustal $\mathrm{W}$ program was used for multiple amino acid sequence comparison, and phylogenetic tree, based on neighbor-joining (NJ) method, was constructed with the program TreeView 1.5.

\section{Computer analyses of sequence data and nucleotide accession numbers}

Computer analyses of nucleotide sequence were performed with GENETYX-MAC v. 9.0 software (Software Development, Tokyo). The search for DNA sequence homology was carried out with the BLAST program of the GenBank Nucleotide Sequence DataLibrary.

The nucleotide sequence of $S$. warneri ISK-1 katA has been submitted to the GenBank databases (accession number AB045340). Accession numbers of other sequences used for the analysis are as follows; $E$. coli katE, M5162; Lactobacillus sakei katA, M84015; Haemophilus influenzae hktE, U02682; Neisseria gonorrhoeae kat gene, U35457; Bacteroides fragilis katB, U187676; Bordetella pertussis katA, U07800; Rhizobium meliloti katA, U59271; Helicobacter pylori katA, U67458; Bacillus subtilis katE, X85182; Bacillus subtilis katA, M80796; Streptomyces coelicolor catB, AF000419; Mycobacterium avium katE, L41246; Pseudomonas aeruginosa katA, U34896.

(A)

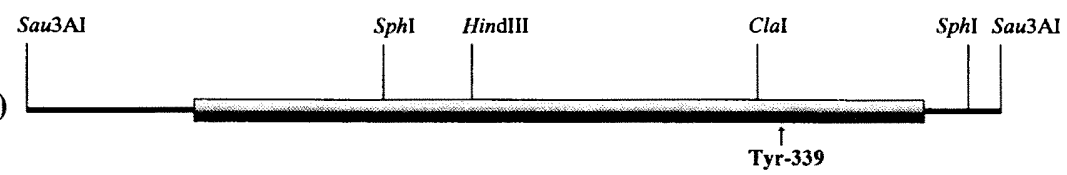

catalase activity

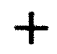

(B)

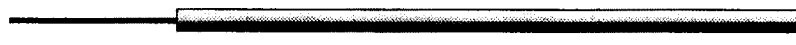

(C)

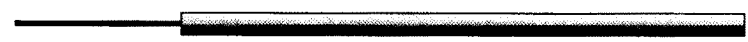

$0.5 \mathrm{~kb}$

Fig. 1. Restriction map and deletion analysis of cloned S. wameri ISK-1 katA locus. Ability to complement catalase activity in E. coli SN0029 was also noted. (A), 2.2-kb Sau3AI fragment; (B) and (C), deleted 2.2-kb fragments corresponding to deletion of 119 and 135 amino acids from the $\mathrm{C}$-terminal region of ISK-1 KatA, respectively. 


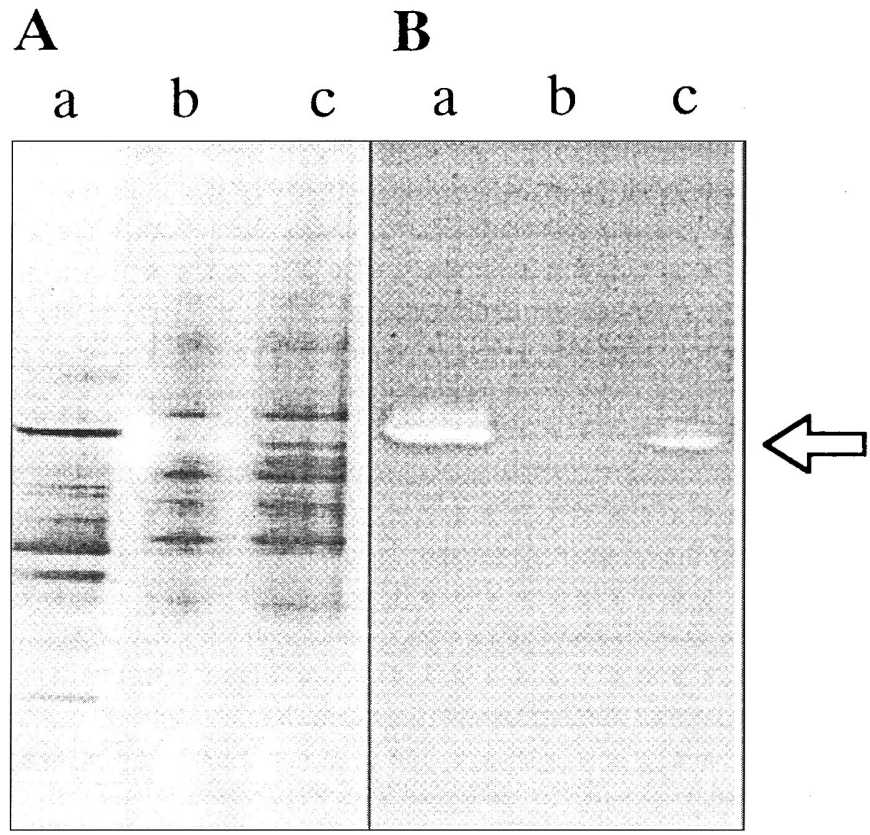

Fig. 2. Expression of ISK-1 katA in E. coli SN0029.

Native PAGE with 7-20\% gradient; A, stained with Coomassie Brilliant Blue; B, stained with diaminobenzidine for catalase band. Lane a, partially purified ISK-1 catalase from $S$. warneri ISK-1 (Mizuno et al., 2000); lane b, cell-free extract from $E$. coli SN0029; lane c, cell-free extract from $E$. coli SN0029 containing katA gene on plasmid pUC18. The white arrow shows the recombinant $k a t A$ gene product expressed in $E$. coli SN0029.

\section{RESULTS}

\section{Cloning of chromosomal $S$. warneri ISK-1 catalase}

The genomic library of $S$. wameri ISK-1 was screened in $E$. coli cells by the addition of $3 \% \mathrm{H}_{2} \mathrm{O}_{2}$, and three positive clones which generated oxygen bubbles were observed. Plasmid DNA pSW103, extracted from one positive clone, contained a 2.2-kb insert DNA fragment (Fig. 1). When E. coli SN0029 was transformed with this plasmid, catalase activity was restored. Thus, we confirmed that expression of catalase activity was due to the presence of pSW103. The cloned catalase gene product expressed in $E$. coli SN0029 showed electrophoretic mobility identical to that of the previously purified catalase from $S$. warneri ISK-1 strain (Fig. 2). This indicates that the cloned catalase gene from $S$. warmeri ISK-1 corresponds to the same enzyme protein as detected and purified from 


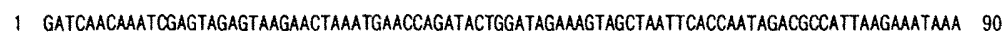

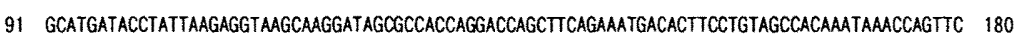

181 CAATTGCGCCACCTATAGCAATCATGGTTATGTGTCTGGAGGTTAAACCTCTTTCATATTATTATCTTCCATATACTGTCTCCCATCTA 270

271 ITTAAATATATCCATCATTTIAATTCTTITAGACCTACTATCAATAGTAATTTAGCACTTTAAAGTAAAATTIAAAAATTTCTGATA 360

361 ATTCGGTTGAGATAGGGGTTAAGTTTCATTAAAAGAGGGATACTTTATAATGGATACTATATTATAATAATTCTAATTTGTGTGGAG 450

451 GgaAATTGAATGTCTAAACAAGACGGTAAGTTAACAGGTTTATTCGGCGCACCOGTGTCAGATAGAGAAAATAGTATGACTGCTGGTCC 540 S.D. MS K Q D G K L T G L F G A P V S D R E N S M T A G P

541 AagAGGTCCACTTITAATGCAGGATATTIACTTCTTAGAGCAAATGTCACATTTGGTCGTGAGGTGATTCCTGAAAGACGTATGCATGC 630 $R G P L L M Q D I Y F L E$ Q $M S$ S H F D R E V I P E R R M H A

631 TAAAGGTTCCGGTGCATTIGGACATTTACCGTAACTAATGATATTACTCAGTATACAAGTGCTAAAATGTTCTCGGAAGTOGGTAAACA 720 $K$ G S G A F G T F T $V$ T N D I T Q Y T S A K M F S E $V$ G K $Q$

721 AACTGAAATGTTCGGGAGATTTCTACTGTATCTGGTGAAGGGGTGCAGCAGATGCTGAGAGAGATATTCGIGGATTTGCATTAAAATT 810 $T E M F A R F S T V S G E R G A$ A D A E R D I R G F A L K F

811 TTATACTGAAGATGGAAACTGGGATTAGTGGTAATAATACGCCCGTATTCTCTTAGAGACCCTAAATTATTCGTAAGCTTAAATAG 900 $Y T E D G N W D L V G N N T P V F F F R D P K L F V S L N R$

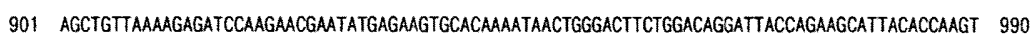
A V K R D P R T N M R S A Q N N W F W T G L P E A L H O V

991 GaCAATITIAATGTCAGATAGAGGTATTCCAAAagATTTACGACATATGCATGGATTCGGTTCACACACATATTCTATGTACAATGATAA 1080

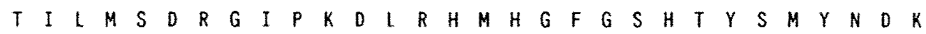

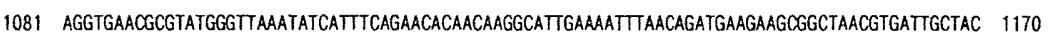

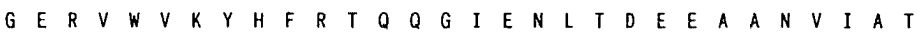

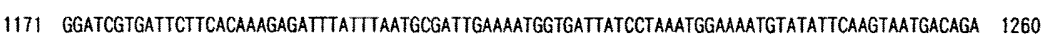

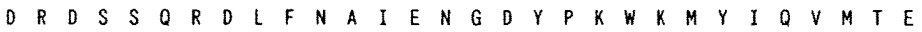

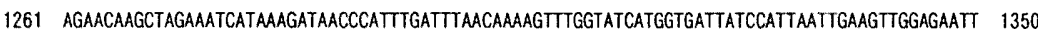
E O A R N H K D N P F D L T K VW Y H G D Y P L I E V G E F 1351 TGAATTAAACCGCAATCCTAATAACTATTTCCAAGATGTTGAACAAGCTGCTTTGCACCTACAAACATCGTTCCTGGTTTAGACTATC 1440 E L N R N P N N Y F Q D V E Q A A F A P T N I V P G L D Y S

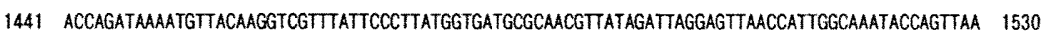
$P D K M L Q G R L F P$ Y G D A Q R Y R L G V N H W Q I P V N 1531 CCAACCTAAagGTGTAGGTATTGAAATTTATGTCCATTTAGTCGTGATGGCCAAATGCGTATTTTAGATGATAACCAAGGTGGCGGACC 1620 Q P K G V G I EN L C P F S R D G Q M R I L D D N Q G G G P

1621 TCATTATTATCCAAATAATCAaGgTGTTIATGATTCCCAACCTGAATTAAAAAGCCGCCATTCCCAGCTGATGGTGATGGTTATGAATA 1710

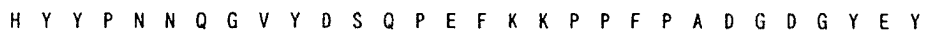

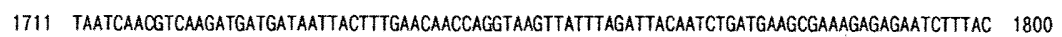
N $O R \quad R \quad Q \quad D \quad D \quad D \quad N$ Y F E Q

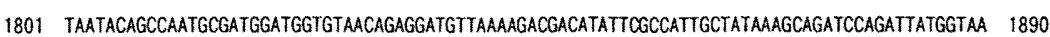
$N$ I A N A M D G V T E D V K R R H I R H C $Y K K A$ A $D$ P D

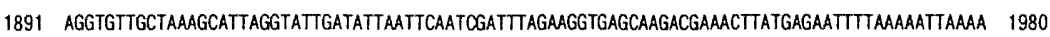
$G \quad V A A K A L G$ I $D$ I $N$ S I D D L E G E O D E T Y

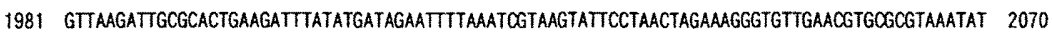

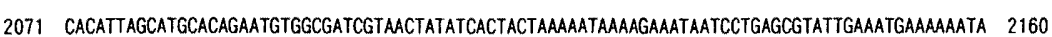

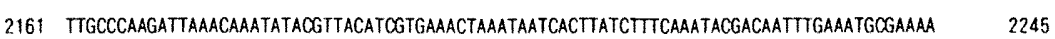

Fig. 3. Nucleotide sequence of the 2.2-kb Sau3AI fragment containing ISK-1 katA and the deduced amino acid sequence. 
ISK-1 strain. The catalase gene located on pSW103 was named as katA.

\section{Nucleotide sequence of $\mathrm{katA}$}

The nucleotide sequence of $2.2-\mathrm{kb}$ Sau $3 \mathrm{AI}$ fragment revealed a single open reading frame of $1,515 \mathrm{bp}$ (Fig. 3). This open reading frame encodes 504 amino acids with a predicted molecular mass of 58,000 Da. The N-terminal amino acid sequence of purified ISK-1 catalase (KatA) was Met-Ser-Lys-GIn-Asp-Gly-Lys-Leu-Thr-Gly-, which corresponds to the deduced one of katA gene. Thus, we confirmed the cloning of the catalase gene from $S$. wameri ISK-1.

The deletion clones used for nucleotide sequence were tested for catalase activity in E. coli SN0029. Deletion of 119 amino acids from the C-terminal region did not affect catalase activity. However, activity was lost when the 135 amino acids were deleted (Fig. 1). This loss of activity may result from the lack of the amino acid residue Tyr- 339 which is one of the essential residues for monofunctional catalase activity as mentioned below.

\section{Comparison of amino acid sequences}

The predicted amino acid sequence obtained for ISK-1 KatA was compared to other catalase sequences in the GenBank-EMBL/Swiss-Prot databases. The KatA showed the highest amino acid identity with Bacteroides fragilis catalase KatB (Rocha and Smith, 1995) (identity $64 \%$ and positive $77 \%$ ) and Haemophilus influenzae catalase HktE

S. warneri ISK-1 KatA

B. fragilis KatB

H. influenzae HktE

L. sakei KatA

E.coli KatE

S. warneri ISK-1 KatA

B. fragilis KatB

H. influenzae HktE

L.sakei KatA

E.coli Kate

S. warneri ISK-1 KatA

B. fragilis KatB

H. influenzae

L. sakei

E.coli
$49 \mathrm{dd}$

108

VIPERRMHAKGSGAFGTFTVTNDITQYTSAKMFSEVGKQTEMFARF STVSGERGAADAER VIPERRMHAKGSGAYGTTFTVTHDITKYTRAAIFSQVGKOTECFVRF STVAGERGAADAER VIPERRMHAKGSGAFGTFTVTHDITKYTRAKIFSEVGKKTEMFARF TTVAGERGAADAER RIPERVVHAKGAGAKGYFKVTKDMSAYTKAAVFSGVGKKTPLITRF SQVAGEAGYPDTYR RIPERIVḦARGSAAHGYFQPYKSLSDITKADFLSDPNKITPVFVRF STVQGGAGSADTVR

$109 \quad d \quad d \quad d \quad 164$

DIRGFALKFYTEDGBWDLVGNNTPVFFFRDPKLFVSLNRAVKRDPRTNMR - ... SAQNNW

DIRGFAMKFYTEEGNWDLVGNNTPVFFLRDPLKFPDLNHAVKRDPRNNMR - . - SANNNW

DIRGFALKFYTEEGNWDLVGNNNTPVFFLRDPRKFPDLNKAVKRDPRTTNMR - . - SATNNW

DVRGFAVKFYTEEGNYDIVGNNNTPVFFVNDPLKFPDFIHSQKRDPRTHAR - ... SQDMQW

DIRGFATKFYTEEGIFDLVGNNTPIFFIQDAHKFPDFVHAVKPEPHWAIPQGQSAHDTFW

285 p

YHGDYPLIEVGEFELNRNPNNYFQDVEQAAFAPTNIVPGLDYSPDKMLQGRLFPYGDAQR

PHKDFPLQDVGILELNRNPENYFAEVEQSAFNPMNIVEGIGFSPDKMLQGRLFSYGDAQR

SKKDYPL IEVGEFELNRNPENFFADVEQSAFAPSNLVPGIGASPDRML QARLFNYADAQR

SQKDYPLIEIGQMVLDENPTNNFEDIOELAFSPANLVPGIEASPDKLLQGRLFGYKDAER

PEELVPVQRVGKMVLNRNPONFFAENEQAAFHPGHIVPGLOFTNDPLLLQGRLFSYTDTQI

Fig. 4. Multiple alignment of the deduced amino acid sequence of ISK-1 KatA with other bacterial catalases.

The active site residues are indicated by underbar. The proximal and distal herne ligand sites are indicated by $p$ and $\mathrm{d}$. 
(Bishai et al., 1994) (identity $66 \%$ and positive 78\%). The KatA also exhibited high homologies to catalases of Lactobacillus sakei (Knauf et al., 1992), Bacillus subtilis, and $E$. coli HPII. No similarities were found to bacterial catalase-peroxidase type enzymes like $E$. coli $\mathrm{HPI}$.

To identify important structural motifs in ISK-1 KatA, multiple alignment of the amino acid sequence of ISK-1 KatA with other catalases was investigated (Fig. 4). The active sites (His-74, Ser-113, and Asn-147) of bovine liver catalase, which is a monofunctional catalase well-investigated in structure (Murthy et al., 1981), were conserved in the KatA at His-56, Ser-95 and Asn-129 positions. Moreover, the proximal heme sites, Pro-335, Arg-353 and Tyr-357 as ligands in bovine liver catalase, were localized as Pro-303, Arg-335 and Tyr-339 in the KatA. Distal heme site ligands in bovine liver catalase were also conserved as His-56, Asn-129, Phe-134 and Phe-142, except that Val-73 was replaced by Met- -55 . The same replacement was also observed in

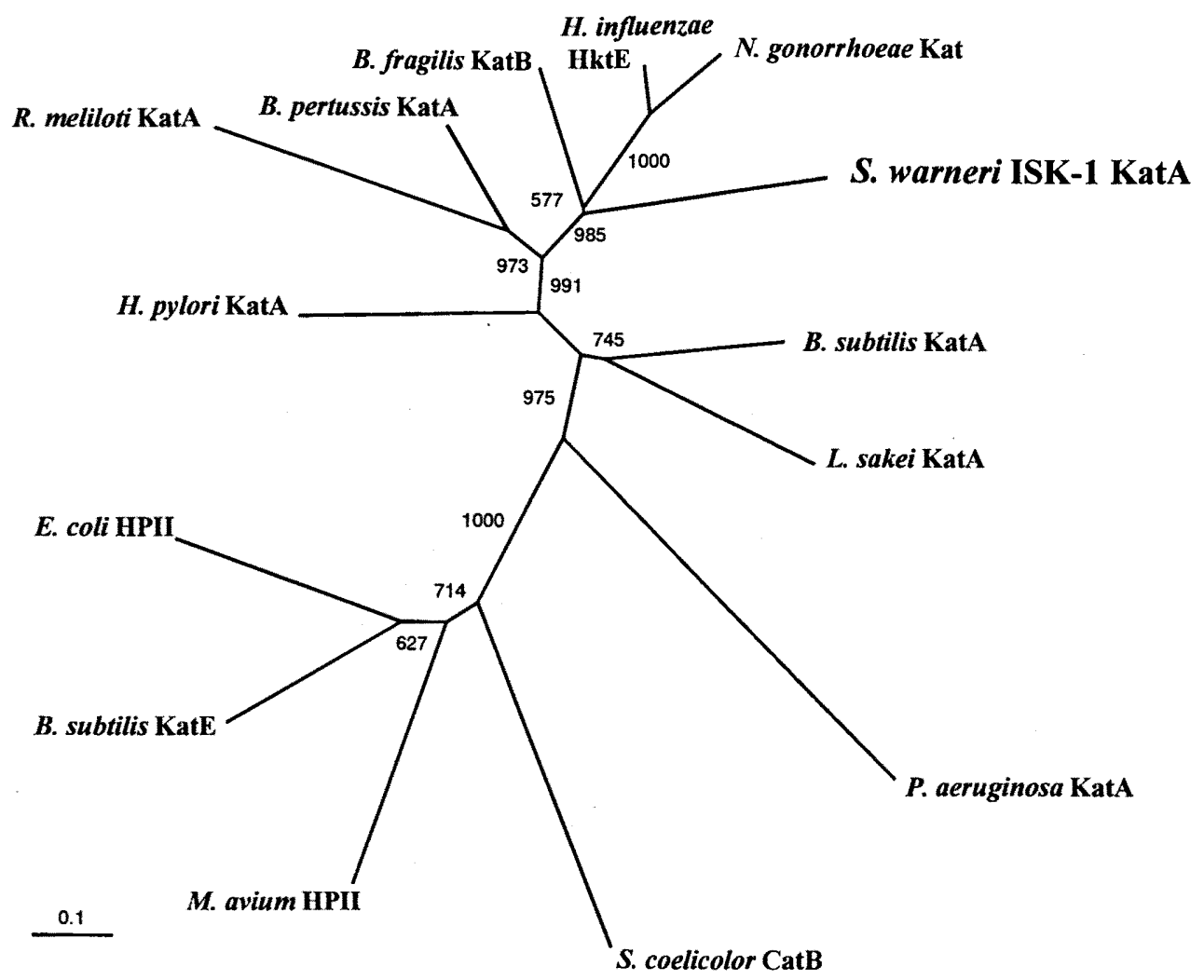

Fig. 5. Phylogenetic relationship of S. wameri ISK-1 KatA and representative microbial monofunctional catalases.

Catalase amino acid sequences used in this analysis were listed in Materials and Methods. 
B. fragilis KatB and H. influenzae HktE.

Phylogenetic relationship between ISK-1 KatA and 13 bacterial monofunctional catalases was determined by the neighbor-joining (NJ) method (Fig. 5). The KatA showed a close relationship with Neisseria gonorrhoeae catalase, B. fragilis KatB and H. influenzae HktE.

\section{DISCUSSION}

In this paper, we cloned and characterized $S$. wameri ISK-1 catalase gene, katA. Expression of katA in $E$. coli SN0029 and catalase activity restored have strongly indicated that cloned katA encodes the catalase of $S$. warneri ISK-1. The KatA structural gene was 1,515 nucleotides long and encoded a protein of 504 amino acids. The previously purified catalase subunit revealed the molecular mass of $64 \mathrm{kDa}$ in the SDS-PAGE gels (Mizuno et al., 2000), which was higher than that of katA gene product $(58 \mathrm{kDa})$ calculated from its predicted amino acid sequence. This discrepancy might be due to a feature of specific protein structure.

The multiple amino acid sequence alignments and phylogenetic analysis showed a strong relationship between ISK-1 KatA and monofunctional catalases. Especially, the KatA showed a high degree of amino acid sequence identity with $B$. fragilis KatB and $H$. influenzae HktE. Based on 16S rDNA phylogenetic analyses, staphylococci are not closely related to these bacteria, although codon usage patterns of catalase genes $k a t A$, $k a t B$ and $h k t E$ are highly similar. These results strongly indicate that there might be a horizontal transfer of the catalase gene from a common ancestor into these strains, and there is no relationship to phylogenies based on phenotype or $16 \mathrm{~S}$ rDNA sequence.

Catalase activity is universal among Staphylococcus spp. Southern blot hybridization analysis revealed that single catalase gene was present in $S$. warneri ISK-1 chromosome (data not shown). On the other hand, high catalase activity of $S$. simulans strain resulted from both of catalase genes encoded on plasmid as well as chromosome (Lynn et $a l ., 1994)$. The catalase gene on the plasmid contributed to the high catalase activity of $S$. simurans. Generally, genes encoded on plasmid DNA are known to transfer with high frequencies, also suggesting that some staphylococcal strains gained several kinds of catalase genes from different ancestors.

In our previous report (Mizuno et al., 2000), we described that the expression behavior of $S$. wameri ISK-1 KatA was similar to that of $B$. fragilis KatB, in the way up-regulated by oxygenation but not peroxides. But unlike B. fragilis KatB, $S$. warmeri ISK-1 KatA was mainly expressed in the exponential growth phase and down-regulated in the stationary growth phase. These suggested that aerobic induction of catalase in $S$. warmeri ISK-1 is independent of peroxides and may be induced via a pathway, which is related to aerobic vegetative metabolism and has not been reported previously as a regulator of catalase expression like RpoS of OxyR. The regulatory system involved in the regulation of $S$. warneri ISK-1 katA should be interesting and is presently under investigation. Thus, the further experiments which include the regulatory analysis of catalase by Northern blotting and construction of catalase-deficient $S$. wameri ISK -1 strain will be needed to give a clear solution about the role of catalase to survive against toxic ROS. 


\section{ACKNOWLEDGEMENT}

We are grateful to S. Nakagawa (Kyowa Hakko Kogyo Co.Ltd.) for the gift of the double catalase mutant $E$. coli SN0029, and helpful suggestions.

\section{REFERENCES}

Berns, K. I. and C. A. Thomas JR 1965 Isolation of high molecular weight DNA from Haemophilus influenzae. J. Mol. Biol., 11: 476-490

Bishai, W. R., H. O. Smith, and G. J. Barcak 1994 A peroxide/ascorbate-inducible catalase from Haemophilus influenzae is homologous to the Escherichia coli katE gene product. J. Bacteriol., 176: $2914-2921$

Christman, M. F., G. Storz, and B. N. Ames 1989 OxyR, a positive regulator of hydrogen peroxide-inducible genes in Escherichia coli and Salmonella typhimurium, is homologous to a family of bacterial regulatory proteins. Proc. Natl. Acad. Sci. USA 86: 3484-3488

Clare, D. A., M. H. Duong, D. Darr, F. Archibald, and I. Fridovich 1984 Effects of molecular oxygen on detection of superoxide radical with nitroblue tetrazolium and on activity strains for catalase. Anal. Biochem., 140: 532-537

Ennahar, S., T. Zendo, K. Sonomoto, and A. Ishizaki 1999 Investigation of bacteriocin production and purification from Nukadoko isolates displaying antimicrobial activity. J. Lactic Acid Bacteria, 10: $29-37$

Flowers, R. S., S. E. Martin, D. G. Brewer, and Z. J. Ordal 1977 Catalase and enumelation of stressed Staphylococcus aureus cells. Appl. Environ. Microbiol., 33: 1112-1117

Hammes, W. P. and Knauf, H. J 1994 Starters in the processing of meat products. Meat Sci., 36: $155-168$

Hassen, H. M. and I. Fridovich 1978 Regulation of the synthesis of catalase and peroxidase in Escherichia coli. J. Biol. Chem., 253: 6445-6450

Imlay, J. A. and S. Linn 1988 DNA damage and oxygen radical toxicity. Science, 240, 1302-1309

Kimura, H., R. Nagano, H. Matshusaki, K. Sonomoto, and A. Ishizaki 1997 A bacteriocin of strain Pediococcus sp. ISK-1 isolated from Nukadoko, bed of fermented rice bran. Biochi. Biotechnol. Biochem., 61: 1049-1051

Knauf, H. J., R. F. Vogel, and W. P. Hammes 1992 Cloning, sequence, and phenotypic expressions of katA, which encodes the catalase of Lactobacillus sake LTH677. Appl. Environ. Microbiol., 58 : 832-839

Loewen, P. C. B. L. Triggs, G. R. Klassen, and J. H. Weiner 1983 Identification and physical characterization of a ColEl hybrid plasmid containing a catalase gene of Esherichia coli. Can. $J$. Biochem. Cell Biol., 61: 1315-1321

Loewen, P. C. and R. Hengge-Aronis 1994 The role of the sigma factor $\sigma^{\text {s }}$ (KatF) in bacterial global regulation. Annu. Rev. Microbiol., 48: 53-80

Lynn, M. F., L. S. Gary, A. L. Paul, and E. H. Harry 1994 Plasmid-encoded catalase of Staphylococcus simulams biovar staphylolyticus. FEMS Microbiol. Lett., 117: 231-236

Mandell, G. R. 1975 Catalase, superoxide dismutase, and virulence of Staphylococcus aureus. J. Clinic. Invest., 55: 561-566

Marmur, J. 1961 A procedure for the isolation of deoxyribonucleic acid from microorganisms. J. Mol. Biol., 3: 208-218

Mizuno, K., M. Kakihara, M. Kohno, T. L. Ha, K. Sonomoto, and A. Ishizaki 2000 Catalase of Staphylococcus warmeri ISK-1 isolated from Nukadoko. J. Fac. Agr., Kyushu Univ., 44: 329-338

Murthy, M. R. N., T. J. Reid II, A. Sicignano, N. Tanaka, and M. G. Rossmann 1981 Structure of beef liver catalase. J. Mol. Biol., 152: 465-499

Nakagawa, S., S. Ishino, and S. Teshiba 1996 Construction of catalase deficient Esherichia coli strains for the production of uricase. Biosci. Biotechnol. Biochem., 60: 415-420

Raymond, J. Z. 1976 Comparative zone electrophoresis of catalase of Staphylococcus species isolated from mammalian skin. Can. J. Microbiol, 22, 1691-1698

Rocha, E. R. and C. J. Smith 1995 Biochemical and genetic analyses of a catalase from the anaerobic 
bacterium Bacteroides fragilis. J. Bacteriol., 177: $3111-3119$

Sambrook, J., E. F. Fritsch, and T. Maniatis 1989 Molecular cloning: a laboratory manual, 2 nd ed. Cold Spring Harbor Press, Cold Spring Harbor, N. $Y$.

Sanger, F., S. Nicklen and A. R. Coulson 1977 DNA sequencing with chain-terminating inhibitors. Proc. Natl. Acad. Sci. USA., 74: 5463-5467

Storz, G., L. A. Tartaglia, S. B. Farr, and B. N. Ames 1990 Bacterial difences against oxidative stress. Trends Genet., 6: 363-368

Triggs-Raine, B. L., B. W. Doble, M. R. Mulvey, P. A. Sorby, and P. C. Loewen 1988 Nucleotide sequence of katG, encoding catalase HPI of Escherichia coli. J. Bacteriol., 170: 4415-4419

von Ossowski, I., G. Hausner, and P. C. Loewen 1991 Nucleotide sequence of Escherichia coli katE, which encodes catalase HPII. J. Bacteriol., 173: 514-520

Yanisch-Perron, C., J. Viera, and J. Messing 1985 A recombination-deficient strain that will support growth of vectors carrying amber mutations and will modify but not restrict transfected DNA. Gene, 33: 103-119 